\title{
A Scrolled Sheet Precursor Route to Niobium and Tantalum Oxide Nanotubes
}

\author{
${ }^{1}$ Yoji Kobayashi, ${ }^{1}$ Hideo Hata, ${ }^{2}$ Magda Salama, ${ }^{1}$ Thomas E. Mallouk ${ }^{*}$
}

${ }^{1}$ Department of Chemistry, The Pennsylvania State University, University Park, Pennsylvania 16802

${ }^{2} 109$ Materials Research Laboratory, Materials Research Institute, The Pennsylvania State University, University Park, Pennsylvania 16802

Supporting Information

\section{Experimental}

$\mathrm{K}_{4} \mathrm{Nb}_{6} \mathrm{O}_{17}, \mathrm{Rb}_{4} \mathrm{Nb}_{3} \mathrm{Ta}_{3} \mathrm{O}_{17}$, and $\mathrm{Rb}_{4} \mathrm{Ta}_{6} \mathrm{O}_{17}$ were prepared by solid state reaction of $\mathrm{K}_{2} \mathrm{CO}_{3}, \mathrm{Nb}_{2} \mathrm{O}_{5}$, and $\mathrm{Ta}_{2} \mathrm{O}_{5} \cdot \mathrm{Rb}_{2} \mathrm{CO}_{3}$ was added in $10 \%$ excess and $\mathrm{K}_{2} \mathrm{CO}_{3}$ was added in $20 \%$ excess to compensate for volatilization of alkali metal oxides. $\mathrm{K}_{4} \mathrm{Nb}_{6} \mathrm{O}_{17}$ was prepared by firing at $1050-1100^{\circ} \mathrm{C}$ for $10-24 \mathrm{hr}$, and $\mathrm{Rb}_{4} \mathrm{Nb}_{3} \mathrm{Ta}_{3} \mathrm{O}_{17}$ at $1100^{\circ} \mathrm{C}$ for $40 \mathrm{hr}$. For $\mathrm{Rb}_{4} \mathrm{Ta}_{6} \mathrm{O}_{17}$ the precursors were fired at $1100^{\circ} \mathrm{C}$ for $40 \mathrm{hr}$ followed by grinding and additional heating at $1200^{\circ} \mathrm{C}$ for $10 \mathrm{hr}$.

The alkali compounds were exchanged to their protonated forms by shaking $0.2 \mathrm{~g}$ in $100 \mathrm{~mL}$ of $2 \mathrm{M}$ nitric or hydrochloric acid for at least 5 days, during which the acid was exchanged three times. After 5 days, the acid was removed by centrifugation and the solid was washed three times with $50 \mathrm{~mL}$ portions of water. Exfoliation was carried out by adding the same batch of protonated material, isolated

\footnotetext{
* Corresponding author email: tom@chem.psu.edu
} 
as a slurry, to aqueous $10 \mathrm{wt} \%$ tetra( $n$-butyl)ammonium hydroxide (TBAOH) solution $(100 \mathrm{~mL})$ and stirring for at least 4 days.

$\mathrm{TBA}_{\mathrm{x}} \mathrm{H}_{1-\mathrm{x}} \mathrm{Nb}_{6} \mathrm{O}_{17}$ was purified by washing away excess TBAOH by centrifugation, and the nanotubes were then precipitated by adding $0.5 \mathrm{M}$ hydrochloric acid. The nanotubes were stirred in the acid solution overnight, and further washed the next day with water (three times) and ethanol (twice). The nanotube product was recovered in powder form by drying at $60^{\circ} \mathrm{C}$.

Colloidal suspensions of the tantalum-substituted compounds in aqueous tetra( $n$-butyl)ammonium hydroxide were sonicated using a Branson 250 Sonifier for 15-45 minutes at an $80 \%$ output level and $70 \%$ duty cycle, before precipitation by slow addition of $100 \mathrm{~mL} 0.5 \mathrm{M} \mathrm{HCl}$ or $0.5 \mathrm{M} \mathrm{NH}_{4} \mathrm{NO}_{3}$ and isolation as a powder.

X-ray diffraction patterns were obtained on a Philips XPert or Scintag Pad diffractometer using $\mathrm{Cu}$ $\mathrm{K}_{\alpha}$ radiation. Nitrogen adsorption isotherms were recorded on either a Micromeritics Accelerated Surface Area and Porosimetry System (ASAP) 2010 or 2020 unit. Pore size analyses was conducted according to either the Barrett, Joyner, and Halenda (BJH) theory, assuming both ends of the pores were open, or NLDFT theory. Before nitrogen adsorption isotherms were acquired, the samples were outgassed for at least 24 hours at $80{ }^{\circ} \mathrm{C}$ for $\mathrm{H}_{4} \mathrm{Nb}_{6} \mathrm{O}_{17} \cdot n \mathrm{H}_{2} \mathrm{O}$ and $120{ }^{\circ} \mathrm{C}$ for $\mathrm{Nb}_{2} \mathrm{O}_{5}$ under dynamic vacuum. Transmission electron microscopy was conducted on either a Philips EM420 (operating at $120 \mathrm{kV}$ ) or JEOL JEM-2010 microscope (operating at 200kV). 


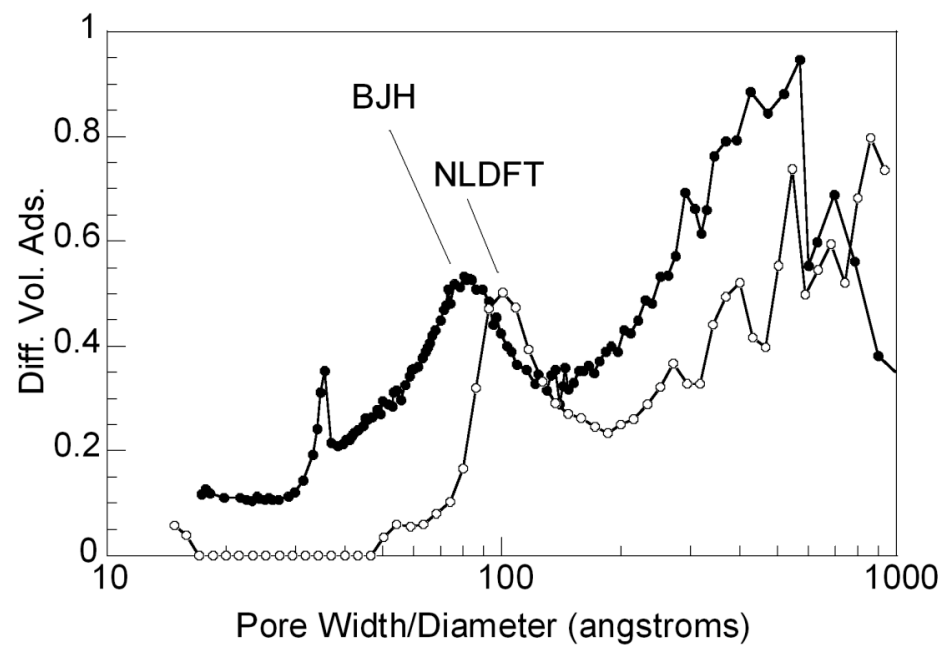

Figure S1. Comparison of pore size distribution of $\mathrm{H}_{4} \mathrm{Nb}_{6} \mathrm{O}_{17} \cdot n \mathrm{H}_{2} \mathrm{O}$ scrolls according to BJH theory (cylindrical pores, measured by diameter) and NLDFT theory (slit pores, measured by pore width).

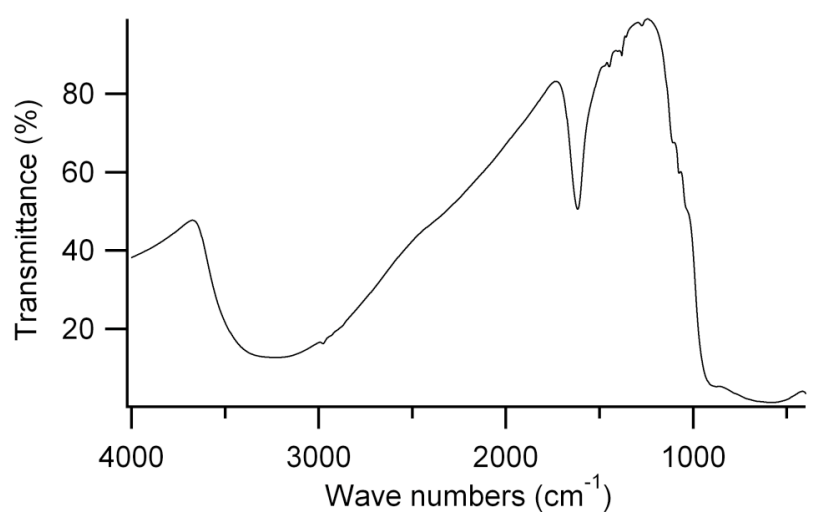

Figure S2. IR spectra of $\mathrm{H}_{4} \mathrm{Nb}_{6} \mathrm{O}_{17} \cdot n \mathrm{H}_{2} \mathrm{O}$. The presence of only a very small peak at approximately $2950 \mathrm{~cm}^{-1}$ (C-H stretching mode) indicates only trace amounts of tetrabutylammonium cations.

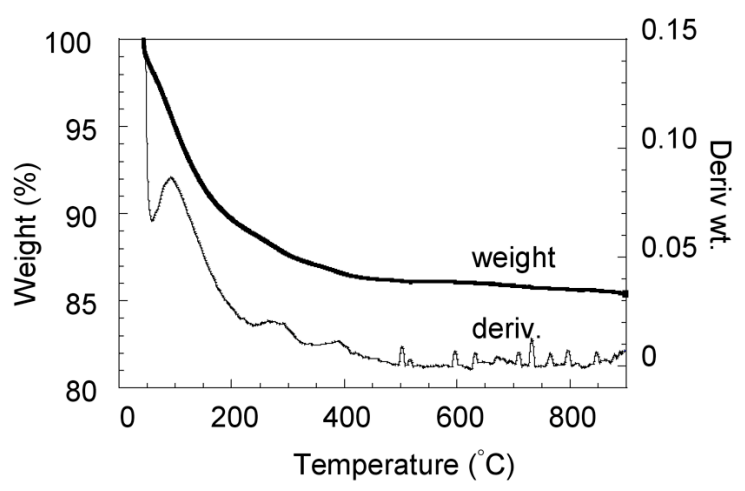

Figure S3. Thermal gravimetry of $\mathrm{H}_{4} \mathrm{Nb}_{6} \mathrm{O}_{17} \cdot n \mathrm{H}_{2} \mathrm{O}$ nanotubes. Data obtained under air, at a ramp rate of $15^{\circ} \mathrm{C} / \mathrm{min}$. 

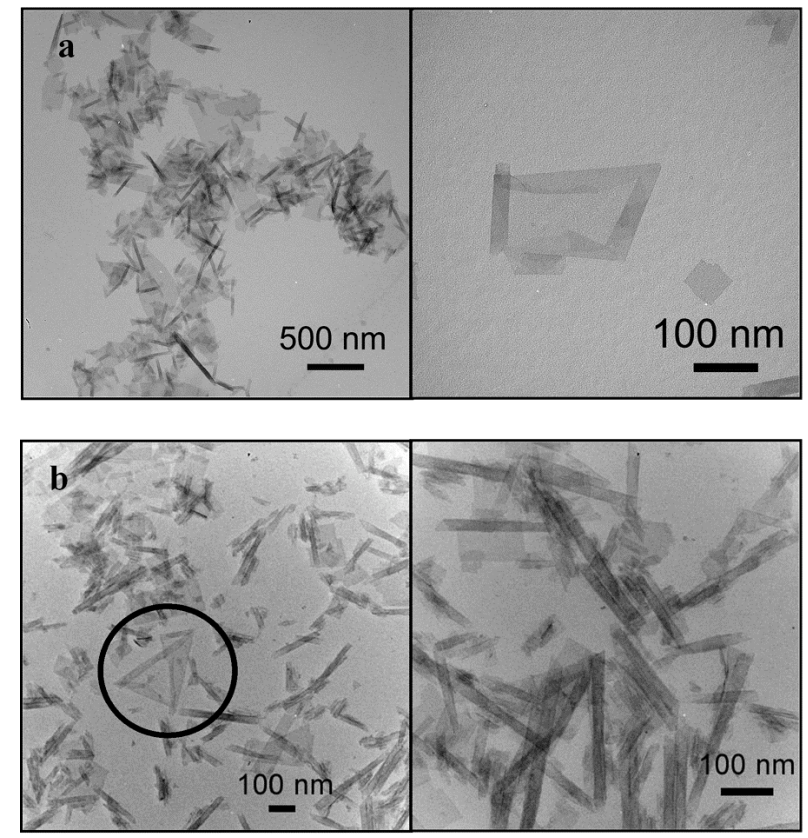

Figure S4. TEM images of (a) $\mathrm{TBA}_{\mathrm{x}} \mathrm{H}_{1-\mathrm{x}} \mathrm{Nb}_{3} \mathrm{Ta}_{3} \mathrm{O}_{17}$ and (b) $\mathrm{TBA}_{\mathrm{x}} \mathrm{H}_{1-\mathrm{x}} \mathrm{Ta}_{6} \mathrm{O}_{17}$. 